\title{
Application of exponential functions in weighted residuals method in structural mechanics. Part II: static and vibration analysis of rectangular plate
}

\author{
I. V. Orynyak ${ }^{1}$ - Yu. P. Bai ${ }^{1}$
}

Received: 9 August 2020 / Accepted: 24 May 2021

\begin{abstract}
The paper is continuation of our efforts on application of the properly constructed sets of exponential functions as the trial (basic) functions in weighted residuals method, WRM, on example of classical tasks of structural mechanics. The purpose of this paper is justification of new method's efficiency as opposed to getting new results. So, static deformation and free vibration of isotropic thin - walled plate are considered here. Another peculiarity of paper is choice of weight (test) functions, where three options are investigated: it is the same as trial one (Galerkin method); it is taken as results of application of differential operator to trial function (least square method); it equals to the second derivative of trial function with respect to both $x$ and $y$ coordinate (moment method). Solution is considered as product of two independent sets of functions with respect to $x$ or y coordinates. Each set is the combination of five consequent exponential functions, where coefficient at first function is equal to one, and four other coefficients are to satisfy two boundary conditions at each opposite boundary. The only arbitrary value in this method is the scaling factor at exponents, the reasonable range of which was carefully investigated and was shown to have a negligible impact on results.

Static deformation was investigated on example of simple supported plate when outer loading is either symmetrical and concentrated near the center or is shifted to any corner point. It was demonstrated that results converge to correct solution much quickly than in classical Navier method, while moment method seems to be a best choice. Then method was applied to free vibration analysis, and again the accuracy of results on frequencies and mode shape were excellent even at small number of terms. At last the vibration of relatively complicated case of clamped-clamped plate was analyzed and very encouraged results as to efficiency and accuracy were achieved.
\end{abstract}

Keywords rectangular plate, clamped-clamped plate, Galerkin method, weighted residual method, free vibration, natural frequecies and modes, weight functions.

\section{Introduction}

The goal of paper consists in further justification of application of the sets of exponential consequent functions [1] for solution of various problems of structural mechanics based on weighted residual method, WRM [2]. WRM is very powerful semi - analytical technique for solving the scientific and engineering problems, and it provides ideas for development of other engineering methods, such as FEM [3]. The essence of WRM consists in proper choice of the trial functions which satisfy to boundary condition. A linear combination of them multiplied on looking for

I. V. Orynyak

orynyak.iv@gmail.com

$\bowtie Y$ Y. P. Bai

ju.p.bai@gmail.com

${ }^{1}$ Igor Sikorsky Kyiv Polytechnic Institute, Kyiv, Ukraine coefficients should also approximately satisfy the governing differential equation, and in this case is considered as an approximate solution. The last goal is achieved integrally: by multiplication of the looking for solution with some number of unknowns on the same number of test (weight) functions, and integration over the whole area [2]. The choice in capacity of test functions the trial ones was historically the first kind and predecessor of WRM, and method is usually named as Galerkin, or Bubnov - Galerkin, or Ritz-Galerkin method [4, 5].

In this work are not investigated any unresolved tasks. Here a new tool for treatment of complicated problem is rather developed. As any new technique the proposed method should be assessed on relatively simple classical problems. Here we consider the rectangular (on example, of square) isotropic plate under bending. In spite of long history and variety of works, it is still treated analytically and attracts many investigators. This task may be 
considered as a testing ground for developing new methods, which can be successfully applied later for more complicated problems [6]. In subsequent review we mostly concentrate on semianalytical approximate methods, which in theory of plates are mostly based and named after Ritz - Galerkin.

Let's start our review from the famous Navier solution. It was proposed at first half of 19th century for the treatment of SSSS rectangular plate (where letter S means one simply supported side, so all four sides are simply supported) [7]. In modern sense it can be considered as the first time application of the Galerkin method. Indeed, if we would consider the sinus function as the Trial ones (which satisfy to boundary condition) and the same function as Test one, we get the pure Galerkin method . Furthermore, as sinus function is the result of $4^{\text {th }}$ order differential equation application to the same function the $\mathrm{Na}-$ vier method can be considered as least square method, LSM, variant of WRM. Furthermore, as sinus results from twice differentiation of sinus, then Navier method can be considered as Moment variant of WRM, because second derivative from displacement is approximately proportional to bending moment. So, this simple contemplation allows to formulate the auxiliary goal of work - to investigate the choice of test function in WRM.

Static analysis can be easily performed if two opposite sides are simple supported. Then one set of functions (say, with respect to $x$ ) are expanded into sinus functions, so for functions along $y$ the simple beam - like ordinary bi - quadratic differential equation is got, which exact solution allows to satisfy any boundary conditions for two other opposite sides. This solution was proposed by Levi [7]. In case of any other boundary condition the auxiliary Levi task is considered for plate with two sides loaded by given bending moment. Then principle of superposition is applied to several Levi tasks to provide the required boundary condition. In practice these strict methods are rather cumbersome, so Galerkin methods are widely applied for static tasks [8], especially for clamped plate [8]. Several trial functions were mention in [8], among themTimoshenko (1910) functions $(1+\cos (\pi x / a))$ for symmetrical loading, Galerkin (1915) functions which contain multipliers $\left(a^{2}-x^{2}\right)^{k}$, where $k \geq 2$.

In vibration analysis both strict methods as well as Ritz - Galerkin methods are equally popular. The origin of strict method is related with work of Voigt (1893) [9]. This work proceeds to idea of Levy but in fact was analogous to it. In case of two opposite simple supported sides the dependence from, say $\mathrm{x}$, is chosen as sinus, which leads for the simple bi - quadratic equation for another coordinate. Its solution allows to get nonlinear characteristic equation for any other boundary conditions. His ideas were lately employed by Leissa [10] for getting accurate nondimensional frequencies. These ideas got further development in work of Gorman [11] who employs the principle of superposition for the dynamical case. This classical solution lays foundation for dynamic stiffness method [12], where displacements at the boundaries and angles are related with moments and forces are related through the frequency dependent matrix.

Returning to the work of Leissa [10] it is interesting to know that for other tasks then two simple supported side he used the approximate Ritz method where the beam vibration solutions, so - called beam functions were chosen as trial function. The idea of using them was elaborated by Warburton (1954) [13] for frequency analysis, who considered them separately (not as combination of them) in Ritz method, and since then these function are among the most widely used.

The increasing complexity of real tasks makes approximate methods more popular. With this respect it worth to mention the work [14] where the comparative study of various approximate solutions (different trial functions) based on Ritz method was performed. It is a pity that it gives no concrete values of frequencies for different methods; it would be valuable reference point for assessment of different techniques. Nevertheless, for us it is important to mention all 6 trial functions employed here. They are as following. First, already mentioned Beam functions, proposed by Young [15] and Warburton [13]. Second, Modified beam functions where trigonometric component remain the same as in Beam functions, whereas the hyperbolic terms are replaced by negative exponential terms [16]. Third, Orthogonal polynomials proposed by Bhat [17], where polynomial sets, satisfied to boundary condition, are orthogonalized by the Gram-Schmidt process. Fourth, keeping in mind that orthogonalization process take a lot of efforts, Kim et al. [18] proposed a set of usual Non-orthogonal polynomials, which integration is much simpler. Fifth, Product of Trigonometric Functions, application of which was suggested by Chai [19]. Sixth, Static beam functions as admissible functions in the Ritz method was first proposed by Zhou [20], which use the polynomials of third order and different sinus terms.

Except the trial functions described in [14] many other different functions are used in literature. For example, the four side clamped plate is analyzed by set of translated on small distance each from other the Sink functions [21], which are the ratio of $\sin (x)$ to $x$. There also many other presentations of trial functions in literature, most of which are combinations of trigonometric functions.

The above analysis shows that our idea [1] of using the sets of consequent exponential functions is, at least, new and deserves deeper investigation. In order to get exhausted understanding of accuracy we will mostly consider the SSSS plate, because, from one hand, there is an exact solution for it. From other hand, this geometry gives no preference for our method, so it would be expected that similar number of terms will give the similar accuracies for other configurations. As example, we will considconsider all sides clamped configuration - which usually present some difficulties in analytical treatment and is very popular for comparison purposes. 


\section{The problem statement and known solution for SSSS plate}

Governing equations. The problem statement will be given from mathematical point of view, without detailed explanation of the physical parameters and derivation of the governing equation. Only two problems will be considered - static loading and free vibration of rectangular plate. Both are reduced to solution of partial differential equation of $4^{\text {th }}$ order with respect to Cartesian coordinates $x$ and $y$ for transversal displacement $w$. So, consider an isotropic elastic rectangular thin plate of thickness $h$, with length $2 a$ and width $2 b$, so $|x| \leq a$ and $|y| \leq b$, as shown in Fig. 1. We also will consider an eccentrically applied loading on rectangular area, so introduce here the center of evenly distributed loading $(\xi, \eta)$, and the dimensions of this area, given by two inequalities $|x-\xi| \leq u,|y-\eta| \leq v$ (Fig. 1).

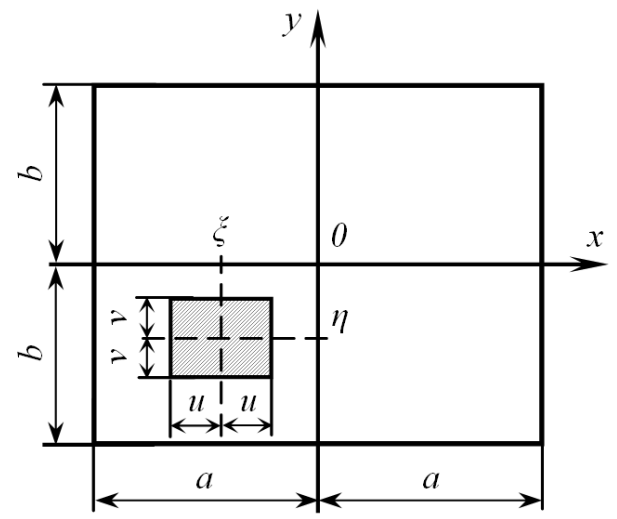

Fig. 1. Partially loaded plate

The problem of static bending of elastic plate reduces to solving an inhomogeneous partial differential equation

$$
\frac{\partial^{4} w}{\partial x^{4}}+2 \frac{\partial^{4} w}{\partial y^{2} \partial x^{2}}+\frac{\partial^{4} w}{\partial y^{4}}=p(x, y)
$$

where $w(x, y)$ is the unknown deflection function of the plate; $p(x, y)$ is an outer loading.

Similarly for free vibration the looking for displacement function is considered as a proportional to function of time, $t: \sin \omega t$, where $\omega$ is a frequency. So, the problem in this case is reduced to a similar equation:

$$
\frac{\partial^{4} w}{\partial x^{4}}+2 \frac{\partial^{4} w}{\partial y^{2} \partial x^{2}}+\frac{\partial^{4} w}{\partial y^{4}}=\omega^{2} w
$$

Once $w$ is known one can calculate the bending moments $M_{x}, M_{y}$ and twisting moment $H$ by the following formulas:

$$
\begin{gathered}
M_{x}=-\left(\frac{\partial^{2} w}{\partial x^{2}}+v \frac{\partial^{2} w}{\partial y^{2}}\right), M_{y}=-\left(\frac{\partial^{2} w}{\partial y^{2}}+v \frac{\partial^{2} w}{\partial x^{2}}\right), \\
H=(1-v) \frac{\partial^{2} w}{\partial x \partial y} .
\end{gathered}
$$

where $v$ is Poisson's ratio.

Thus, the problem is reduced to finding the deflection function, which simultaneously satisfies equation (1) and the boundary conditions on the plate contour. Here, we consider only two types of boundary conditions:

1. The plate is simply supported at all edges. The analytical expressions for the boundary conditions in this case reduce to:

$$
\begin{gathered}
w(x= \pm a, y)=0, \\
M_{x}(x= \pm a, y)=0 \Rightarrow \frac{\partial^{2} w}{\partial x^{2}}(x= \pm a, y)=0 . \\
w(x, y= \pm b)=0, \\
M_{y}(x, y= \pm b)=0 \Rightarrow \frac{\partial^{2} w}{\partial y^{2}}(x, y= \pm b)=0 .
\end{gathered}
$$

2. The plate is clamped (or built - in) at all edges. The boundary conditions in this case are:

$$
\begin{array}{ll}
w(x= \pm a, y)=0, & \frac{\partial w}{\partial x}(x= \pm a, y)=0 \\
w(x, y= \pm b)=0, & \frac{\partial w}{\partial y}(x, y= \pm b)=0
\end{array}
$$

Classical Navier method. It is presented for simply supported plate in many textbooks. In case of uniformly distributed loading $p$ over the area of the rectangle, as shown in Fig. 1, the displacements are given by the following expression [7]:

$$
\begin{gathered}
w(x, y)=\frac{1}{\pi^{4} D} \sum_{m=1}^{N_{1}} \times \\
\times \sum_{n=1}^{N_{1}} \frac{a_{m n}}{\left(\frac{m^{2}}{a^{2}}+\frac{n^{2}}{b^{2}}\right)^{2}} \sin \frac{m \pi x}{a} \sin \frac{n \pi y}{b} \\
a_{m n}=\frac{4 p}{m n u v} \sin \frac{m \pi \xi}{a} \sin \frac{n \pi \eta}{b} \sin \frac{m \pi u}{2 a} \sin \frac{n \pi v}{2 b}
\end{gathered}
$$

where $N_{1}$ is the upper limit of expansion terms, which predetermines the accuracy. Similarly, for free vibration problem the displacement field is sought in the following form: 


$$
w_{k, n}(x, y)=\sin \frac{k \pi x}{a} \sin \frac{n \pi y}{b}
$$

which gives from (1b) the following values of natural frequencies:

$$
\omega_{k, n}=\pi^{2}\left(\left(\frac{k}{a}\right)^{2}+\left(\frac{n}{b}\right)^{2}\right)
$$

Note that displacements (6a) actually are the vibration modes.

\section{Proposed Method}

System of trial functions. For the sake of convenience we introduce the following designations for exponential functions, let:

$$
\Gamma_{k}\left(x, L_{x}\right)=\exp \left(\frac{k x}{L_{x}}\right) ; \Gamma_{m}\left(y, L_{y}\right)=\exp \left(\frac{m y}{L_{y}}\right),
$$

where $k, m$ are integers, and $L_{x}$ and $L_{y}$ are scaling parameters, which values are comparable with characteristic dimensions of the plate. In some sense these are arbitrary ones, and, we think, that necessity of their involvement was the main hindrance, preventing application of exponential functions so far. So, we will explore the influence of them on the results accuracy.

The next main step in our analysis is construction of the sets of trial function, designated below as $\Phi_{k}(x)$ and $\Phi_{m}(y)$, with respect to any coordinates. Taking in mind that each trial functions should satisfy 4 boundary conditions (two on each side), take them as the sum of five consecutive exponential functions $\Gamma_{k}\left(x, L_{x}\right)$ and $\Gamma_{m}\left(y, L_{y}\right)$ in the following form:

$$
\Phi_{k}(x)=\alpha_{k, 0} \exp \left(\frac{(k+2) x}{L_{x}}\right)+\alpha_{k, 1} \exp \left(\frac{(k+1) x}{L_{x}}\right)+
$$

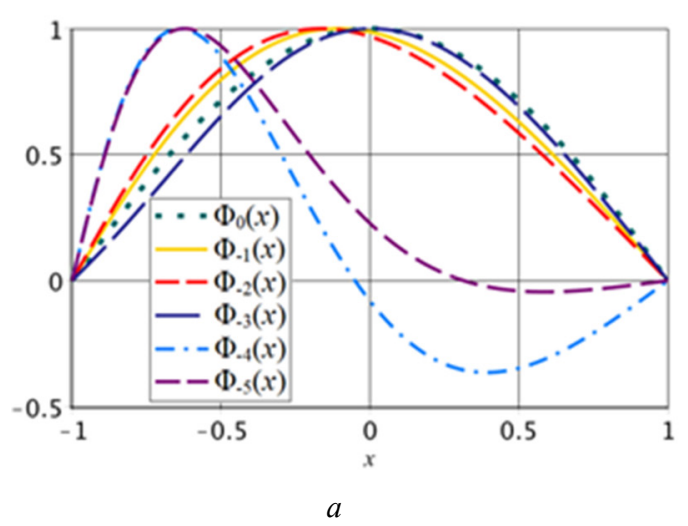

$$
\begin{gathered}
+\alpha_{k, 2} \exp \left(\frac{k x}{L_{x}}\right)+\alpha_{k, 3} \exp \left(\frac{(k-1) x}{L_{x}}\right)+ \\
+\alpha_{k, 4} \exp \left(\frac{(k-2) x}{L_{x}}\right)= \\
=\sum_{i=0}^{4} \alpha_{k, i} \Gamma_{2+k-i}\left(x, L_{x}\right), K_{1} \leq k \leq K_{2} .
\end{gathered}
$$

And similarly:

$$
\Phi_{m}(y)=\sum_{j=0}^{4} \gamma_{m, j} \Gamma_{2+m-j}\left(y, L_{y}\right), M_{1} \leq m \leq M_{2}
$$

where the first coefficients $\alpha_{k, 0}$ and $\gamma_{m, 0}$ are supposed to be equal 1 , and all other coefficients $\alpha_{k, i}, \gamma_{m, j}(i, j=\overline{1,4})$ are calculated from the boundary conditions (3a), (3b) or (4a), (4b). So all coefficients $\alpha_{k, i}$ and $\gamma_{m, j}$ of trial functions for given geometry are calculated in advance, and the trial functions (sets of consecutive exponential functions) are exactly known. As example of their determination for simple supported plate (3), on Fig. 2, $a$ are shown the several trial functions $\Phi_{k}(x), L_{x}=2, k=\overline{-5,0}$, normalized on their maximum value. It is worth to note that function $\Phi_{0}(x)$ is a symmetrical one, while maximum of functions $\Phi_{k}(x)$ with negative $k$ are mostly shifted to left side of plate (negative $x$ ); and vise versa, functions $\Phi_{k}(x)$ with positive $k$ mostly attain their maximum at positive $x$. On Fig. 2, $b$ are shown the second derivatives of these functions, $\Phi_{k}^{\prime \prime}(x), k=\overline{-5,0}$, which can be used for calculation of bending moments (also, they will be tried as weight functions in WRM, too). Note, that sometimes (for symmetrical loading) we will use different from $(7 b)-(7 c)$ numeration of lower indexes. This case will be additionally explained later. Next step is introduction of two dimensional basic functions $\Psi_{k, m}(x, y)$ which are product of $1 \mathrm{D}$ sets of trial functions:

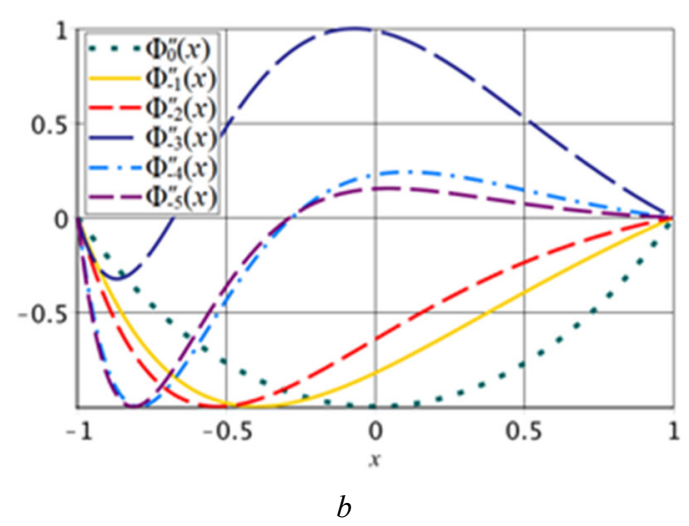

Fig. 2. Sets of trial functions ( $a$ ), and their second derivatives $(b), a=1, L_{x}=2$ 


$$
\begin{gathered}
\Psi_{k, m}(x, y)=\Phi_{k}\left(x, L_{x}\right) \cdot \Phi_{m}\left(y, L_{y}\right) \\
w(x, y)=\sum_{k=K_{1}}^{K_{2}} \sum_{m=M_{1}}^{M_{2}} \beta_{k, m} \Psi_{k, m}(x, y),
\end{gathered}
$$

where $\beta_{k, m}$ are coefficients to be found. Inserting (7a), (7b) in (8) we get:

$$
\begin{gathered}
w(x, y)=\sum_{k=K_{1}}^{K_{2}} \sum_{m=M_{1}}^{M_{2}} \beta_{k, m} \sum_{i=0}^{i=4} \alpha_{k, i} \times \\
\times \sum_{j=0}^{j=4} \gamma_{m, j} \Gamma_{2+k-i}\left(x, L_{x}\right) \Gamma_{2+m-j}\left(y, L_{y}\right)
\end{gathered}
$$

Weight functions and system of algebraic equations for static case. Insert 2D trial functions $\Psi_{k, m}(x, y)$ (8) in governing equations (1a). Application of differential operator to each trial function gives the following function $\Omega_{k, m}(x, y)$ :

$$
\begin{gathered}
\Omega_{k, m}(x, y)=\Phi_{k}^{I V}(x) \cdot \Phi_{m}(y)+2 \Phi_{k}^{I I}(x) \times \\
\times \Phi_{m}^{I I}(y)+\Phi_{k}(x) \cdot \Phi_{m}^{I V}(y)
\end{gathered}
$$

Which can be easily expanded in terms of elementary exponential functions $\Gamma_{k}$ :

$$
\begin{aligned}
\Omega_{k, m}(x, y) & =\sum_{i=0}^{i=4} \sum_{j=0}^{j=4} \lambda_{k, m}^{i, j} \Gamma\left(2+k-i, x, L_{x}\right) \times \\
& \times \Gamma\left(2+m-j, y, L_{y}\right)
\end{aligned}
$$

where

$$
\lambda_{k, m}^{i, j}=\alpha_{k, i} \gamma_{m, j}\left(\left(\frac{2+k-i}{L_{x}}\right)^{2}+\left(\frac{2+m-j}{L_{y}}\right)^{2}\right)^{2}
$$

Introduce also auxiliary functions $\Theta_{k, m}(x, y)$, which are to be used as weight functions too. They are derived by twice differentiation of $\Psi_{k, m}(x, y)$ by both coordinates:

$$
\Theta_{k, m}(x, y)=\Phi_{k}^{\prime \prime}(x) \cdot \Phi_{m}^{\prime \prime}(y) .
$$

This gives the following:

$$
\begin{aligned}
\Theta_{k, m}(x, y)= & \sum_{i=0}^{i=4} \sum_{j=0}^{j=4} \kappa_{k, m}^{i, j} \Gamma\left(2+k-i, x, L_{x}\right) \times \\
& \times \Gamma\left(2+m-j, y, L_{y}\right)
\end{aligned}
$$

where

$$
\kappa_{k, m}^{i, j}=\alpha_{k, i} \gamma_{m, j}\left(\left(\frac{2+k-i}{L_{x}}\right)^{2}+\left(\frac{2+m-j}{L_{y}}\right)^{2}\right) .
$$

As it was said above and was investigated in our previous work [1], three functions: $\Psi_{k, m}(x, y)$,
$\Theta_{k, m}(x, y)$ and $\Omega_{k, m}(x, y)$ can be used as the weight functions in WRM. In first case we have Galerkin method, second one we name as moment method (it completely differs from the same name method mentioned in [2]), and third method is least square method, LSM.

It is convenient in general presentation (9a) to substitute two indexes $k, m$ by one index $Z$ :

$$
\begin{aligned}
& Z=\left(k-K_{1}\right) \cdot\left(M_{2}-M_{1}+1\right)+\left(m-M_{1}\right)+1, \\
& 1 \leq Z \leq\left(M_{2}-M_{1}+1\right)\left(K_{2}-K_{1}+1\right)
\end{aligned}
$$

In the following we will take equal number of the sets with respect to both coordinates. So instead of (9a) we can write for looking for displacement:

$$
w(x, y)=\sum_{Z=1}^{(N+1)^{2}} \beta_{Z} \Psi_{Z}(x, y),
$$

where $N=M_{2}-M_{1}=K_{2}-K_{1}$. To apply Galerkin method we need to similarly introduce the system of weight functions constructed in same way as $\Psi_{Z}(x, y)$, which however has the different numeration:

$$
\Psi_{Y}(x, y)=\Phi_{r}(x) \Phi_{q}(y),
$$

where

$$
\begin{aligned}
& Y=\left(r-K_{1}\right)(N+1)+\left(q-M_{1}\right)+1, \\
& 0 \leq\left(r-K_{1}\right),\left(q-M_{1}\right) \leq N, 1 \leq Y \leq(N+1)^{2} .
\end{aligned}
$$

Substitute the general solution (11a) in left side of equation (1a). Then consequently multiply both sides of (1a) on weight functions taken in form (11c). Then take the integrals over the whole plate area, and in this way get the system of linear equations:

$$
\phi_{k, m}^{r, q} \beta_{k, m}=\phi_{Z}^{Y} \beta_{Z}=a_{Y},
$$

where

$$
\begin{gathered}
\phi_{k, m}^{r, q}=\int_{-b}^{b} \int_{-a}^{a} \sum_{i=0}^{i=4} \sum_{j=0}^{j=4} \lambda_{k, m}^{i, j} \Gamma_{2+k-i}\left(x, L_{x}\right) \times \\
\times \Gamma_{2+m-j}\left(y, L_{y}\right) \sum_{s=0}^{4} \alpha_{r, s} \Gamma_{2+r-s}\left(x, L_{x}\right) \times \\
\times \sum_{t=0}^{4} \gamma_{q, t} \Gamma_{2+q-t}\left(y, L_{y}\right) d x d y, \\
a_{Y}=\int_{-b}^{b} \int_{-a}^{a} p(x, y) \Psi_{Y}(x, y) d x d y= \\
=\int_{-b}^{b} \int_{-a}^{a} p(x, y) \Phi_{r}(x) \Phi_{q}(y) d x d y
\end{gathered}
$$

As we can see, invaluable advantage of the exponential functions is that they are very easily differentiated and integrated in closed form. So, in determining the coefficients in (11f) it should be accounted for, that: 


$$
\begin{gathered}
\int_{-a}^{a} \Gamma_{2+k-i}\left(x, L_{x}\right) \cdot \Gamma_{2+r-s}\left(x, L_{x}\right) d x= \\
=\frac{L_{x}}{4+k-i+r-s}\left(\Gamma_{4+k-i+r-s 1}\left(a, L_{x}\right)-\right. \\
\left.\quad-\Gamma_{4+k-i+r-s}\left(-a, L_{x}\right)\right) .
\end{gathered}
$$

The terms in free column $(11 \mathrm{~g})$ are also easily taken analytically:

$$
\begin{gathered}
a_{Y}=\int_{-b}^{b} \int_{-a}^{a} p(x, y) \Phi_{r}(x) \Phi_{q}(y) d x d y= \\
=\int_{\xi-u}^{\xi+u} \int_{\eta-v}^{\eta+v} \sum_{i=0}^{4} \alpha_{r, i} \Gamma_{2+r-i}\left(x, L_{x}\right) \times \\
\times \sum_{j=0}^{4} \gamma_{q, j} \Gamma_{2+q-j}\left(y, L_{y}\right) d x d y= \\
=\sum_{i=0}^{4} \frac{\alpha_{r, i}}{2+r-i}\left(\Gamma_{2+r-i}\left(\xi+u, L_{x}\right)-\Gamma_{2+r-i}\left(\xi-u, L_{x}\right)\right) \times \\
\times \sum_{j=0}^{4} \frac{\gamma_{q, j}}{2+q-j}\left(\Gamma_{2+q-j}\left(\eta+v, L_{y}\right)-\right. \\
\left.-\Gamma_{2+q-j}\left(\eta-v, L_{y}\right)\right)
\end{gathered}
$$

which is correct when $2+q-j \neq 0$ and $2+r-i \neq 0$.

Otherwise:

$$
\begin{gathered}
\frac{\alpha_{r, i}}{2+r-i}\left(\Gamma_{2+r-i}(\xi+u)-\Gamma_{2+r-i}(\xi-u)\right)= \\
=\alpha_{r, i} \cdot u \text { if } 2+r-i=0, \\
\frac{\gamma_{q, j}}{2+q-j}\left(\Gamma_{2+q-i}(\eta+v)-\Gamma_{2+q-i}(\eta-v)\right)= \\
=\gamma_{q, j} \cdot v \text { if } 2+q-j=0 .
\end{gathered}
$$

It is no need to describe in details the application of $\Theta_{k, m}(x, y)$ and $\Omega_{k, m}(x, y)$ in capacity of weight function. We only note, that in first case coefficients $\alpha_{r, s}$ and $\gamma_{q, t}$ in (11f) should be substituted by $\frac{\alpha_{r, s}}{\left(L_{x}\right)^{2}}(2+r-s)^{2}$ and $\frac{\gamma_{q, t}}{\left(L_{y}\right)^{2}}(2+q-t)^{2}$ respectively, and the same is related to equation (11g) or its expanded form (12b). And in second case, i.e. LSM is situation is the similar - the products of $\alpha_{r, s}$ and $\gamma_{q, t}$ should be replaced by $\lambda_{r, q}^{s, t}$.

Algebraic equations for free vibration. A prominent advantage of approximate WRM over the exact analytical methods is that its general scheme of application is almost the same for both static and free vibration cases. This allows us to describe the theoretical part very briefly. Besides, we consider only Galerkin method. The reason is very simple. As it will be shown for static case, Galerkin method is very good one with respect to calculation of displacements, and mode shape analysis is actually the investigation of the displacement.

So, we take the looking for displacements in form (11b). Insert them in governing equation (1b), so we get the expression for residuals $\Omega_{k, m}(x, y)$ :

$$
\begin{aligned}
\Omega_{k, m}(x, y)= & \sum_{i=0}^{i=4} \sum_{j=0}^{j=4} \lambda 1_{k, m}^{i, j} \Gamma\left(2+k-i, x, L_{x}\right) \times \\
& \times \Gamma\left(2+m-j, y, L_{y}\right)
\end{aligned}
$$

where the following designation for coefficients $\lambda 1_{k, m}^{i, j}$ is used:

$$
\begin{gathered}
\lambda 1_{k, m}^{i, j}=\alpha_{k, i} \gamma_{m, j}\left(\left(\left(\frac{2+k-i}{L_{x}}\right)^{2}+\left(\frac{2+m-j}{L_{y}}\right)^{2}\right)^{2}-\omega^{2}\right)= \\
=\lambda_{k, m}^{i, j}-\alpha_{k, i} \gamma_{m, j} \omega^{2}
\end{gathered}
$$

which now is the sum of two constituents, the first one is the same as in static case, namely $\lambda_{k, m}^{i, j}$, and other one is proportional to $\omega^{2}$. Then residuals (13a) are consequently multiplied on weight functions (11c) and integrated over the area. Eventually we get the following equation for coefficients of the matrix:

$$
\begin{gathered}
\phi_{k, m}^{r, q}=\phi 0_{k, m}^{r, q}-\phi 1_{k, m}^{r, q} \omega^{2}= \\
=\int_{-b-a}^{b} \int_{i=0}^{a} \sum_{j=0}^{4} \sum_{j=0}^{4}\left(\lambda_{k, m}^{i, j}-\alpha_{k, i} \gamma_{m, j} \omega^{2}\right) \times \\
\times \Gamma_{2+k-i}\left(x, L_{x}\right) \cdot \Gamma_{2+m-j}\left(y, L_{y}\right) \times \\
\times \sum_{s=0}^{4} \alpha_{r, s} \Gamma_{2+r-s}\left(x, L_{x}\right) \sum_{t=0}^{4} \gamma_{m, t} \Gamma_{2+q-t}\left(y, L_{y}\right) d x d y
\end{gathered}
$$

All integrals in (13c) can be easily taken analytically, as was shown in (12a) and (12b). So, resulting system of algebraic equation with accounting for index redesignation takes the form:

$$
\left(\begin{array}{ccccc}
\phi 0_{1}^{1}-\omega^{2} \cdot \phi 1_{1}^{1} & \phi 0_{2}^{1}-\omega^{2} \cdot \phi 1_{2}^{1} & \ldots & \phi 0_{(N+1)^{2}}^{1}-\omega^{2} \cdot \phi 1_{(N+1)^{2}}^{1} \\
\phi 0_{1}^{2}-\omega^{2} \cdot \phi 1_{1}^{2} & \phi 0_{2}^{2}-\omega^{2} \cdot \phi 1_{2}^{2} & \ldots & \phi 0_{(N+1)^{2}}^{2}-\omega^{2} \cdot \phi 1_{(N+1)^{2}}^{2} \\
\ldots & \ldots & \ldots & \ldots \\
\ldots & \ldots & \ldots & \phi 0_{(N+1)^{2}}^{(N+1)^{2}}-\omega^{2} \cdot \phi 1_{(N+1)^{2}}^{(N+1)^{2}}
\end{array}\right) \times
$$

$$
\times\left\{\begin{array}{c}
\beta_{1} \\
\beta_{2} \\
\cdots \\
\beta_{(N+1)^{2}}
\end{array}\right\}=\left\{\begin{array}{c}
0 \\
0 \\
\cdots \\
0
\end{array}\right\}
$$


System (13d) has only solution when its determinant is equal to zero. This allows finding the natural frequencies. After, the natural modes can be easily found by usual procedure.

Simply - supported plate, static centric load. This is a special case of static loading. Of course, it can be treat treated by the proposed procedure. Yet here we wish to show other possibility of construction of the trial functions as the sets of consequent exponential functions. Consider SSSS plate $|x| \leq a,|y| \leq b$, loaded by uniformly distributed stresses, $q(x, y)$, at the central rectangular part, $|x| \leq u,|y| \leq v$, of the plate, so:

$$
q(x, y)=\frac{1}{u v} \cdot\left\{\begin{array}{cc}
1, & -u \leq x \leq u, \quad-v \leq y \leq v, \\
0, & \text { elsewhere. }
\end{array}\right.
$$

Symmetrical case makes redundant a lot of general sets of trial functions ( $7 b)$ and (7c). So, the more efficient symmetrical trial functions can be proposed. First of all wrote the specific boundary conditions at $x=0, y=0$ :

$$
\begin{array}{ll}
\frac{\partial w}{\partial x}(x=0)=0, & \frac{\partial^{3} w}{\partial x^{3}}(x=0)=0 \\
\frac{\partial w}{\partial y}(y=0)=0, & \frac{\partial^{3} w}{\partial y^{3}}(y=0)=0 .
\end{array}
$$

Note that on sides $(x=+a, y)$ and $(x, y=+b)$ the boundary conditions remain the same as are given by formulas (3a) and (3b). So, we will use here the discontinuous decaying functions, as were proposed in [1]. Construct the following sets of 5 consequent exponential functions which decay at infinity $x \rightarrow \pm \infty$ :

$$
\begin{gathered}
\Phi_{k}(x)=\alpha_{k, 0} \exp \left(-\frac{k x}{L_{x}}\right)+\alpha_{k, 1} \exp \left(-\frac{(k+1) x}{L_{x}}\right)+ \\
+\alpha_{k, 2} \exp \left(-\frac{(k+2) x}{L_{x}}\right)+\alpha_{k, 3} \exp \left(-\frac{(k+3) x}{L_{x}}\right)+ \\
+\alpha_{k, 4} \exp \left(-\frac{(k+4) x}{L_{x}}\right)=\sum_{i=0}^{4} \alpha_{k, i} \Gamma_{-k-i}\left(x, L_{x}\right) .
\end{gathered}
$$

In $y$-direction the sets of functions $\Phi_{m}(y)$ are constructed in the same manner:

$$
\Phi_{m}(y)=\sum_{i=0}^{4} \gamma_{m, j} \Gamma_{-m-j}\left(x, L_{y}\right)
$$

As before, take that all coefficients $\alpha_{k, 0} \quad \gamma_{m, 0}$ as equal to 1 , and all other coefficients $\alpha_{k, i}(i=\overline{1,4})$ and $\gamma_{m, j}(j=\overline{1,4})$ are determined from the boundary conditions (3a) and (3b) at $(x=+a, y)$ and $(x, y=+b)$ as well as from the symmetry conditions (15a) and (15b).
The next step is introduction of $2 \mathrm{D}$ trial functions $\Psi_{k, m}(x, y)$ according to formula (8). All other steps are also the same, except some technical details, for example integration is performed over $1 / 4$ of the whole area, and $K_{1}=M_{1}=0, K_{2}=M_{2}=N$.

\section{Practical tasks, verification}

Due to the methodological character of the present work we will consider below only square plates, each side being equal to 1 , i. e. $a=b=1$. Also we always take $L_{x}=L_{y}=L$. The choice of this rather arbitrary parameter on the predicted results will be investigated. For static loading the results are presented for both displacements (as the looking for target function) and for bending moment, which is mostly important in structural analysis. For vibration analysis only frequencies and, sometimes, mode shapes will be calculated.

Static centric loading. Take that loading is given by (14) and $u=v$. Accurate results are given and calculated by Navier formulas. It approximately stated that correct solution can be attained at number of terms of expansion $N_{1}$ in formula (5) equal to 400 , i. e. $400 \cdot 400$ coefficients $a_{m, n}$ are used.

Uniformly distributed loading is a very trivial case, which requires a small number of terms. So, we will consider more concentrated cases of loading. Start with loading on $1 / 2$ of the plate area, i. e. take that $u / a=0.5$. Fig. 3, $a$ shows the accurate Navier $\left(N_{1}=400\right)$ displacement along axis $x=y$. Fig. 3, $b$ and Fig. 3, $c$ show the deviation of approximate results for displacement from the accurate one, $\delta\left(w_{\alpha, N}(x, y)\right)$ for number of terms in WRM $N$ equal to 4 and 8. Fig. $3 c, d$, e shows the exact distribution of the bending moments along axis $x=y$, and the deviations of the moments, $\delta\left(M_{\alpha, N}(x, y)\right)$ from exact value according to three different variants of choice of test functions. These deviations are calculated by the following expressions:

$$
\begin{gathered}
\delta\left(w_{\alpha, N}(x, y)\right)=\frac{w_{\text {exact }}(x, y)-w_{\alpha, N}(x, y)}{w_{\text {exact }}^{\max }(x, y)} \cdot 100 \%, \\
\delta\left(M_{\alpha, N}(x, y)\right)=\frac{M_{\text {exact }}(x, y)-M_{\alpha, N}(x, y)}{M_{\text {exact }}^{\max }(x, y)} \cdot 100 \%,
\end{gathered}
$$

where $w_{\text {exact }}^{\max }(x, y)$ and $M_{\text {exact }}^{\max }(x, y)$ are the maximal "exact" (for $N_{1}=400$ ) Navier values, here attained at the point $(x=0, y=0)$. Index “ $\alpha$ " $(\alpha=\{\Psi, \Theta, \Omega\})$ relates to our investigations of the best variant of WRM: namely, for the Galerkin method $\alpha=\Psi$, for the method of moments $\alpha=\Theta$ and for the least square method $\alpha=\Omega$. 

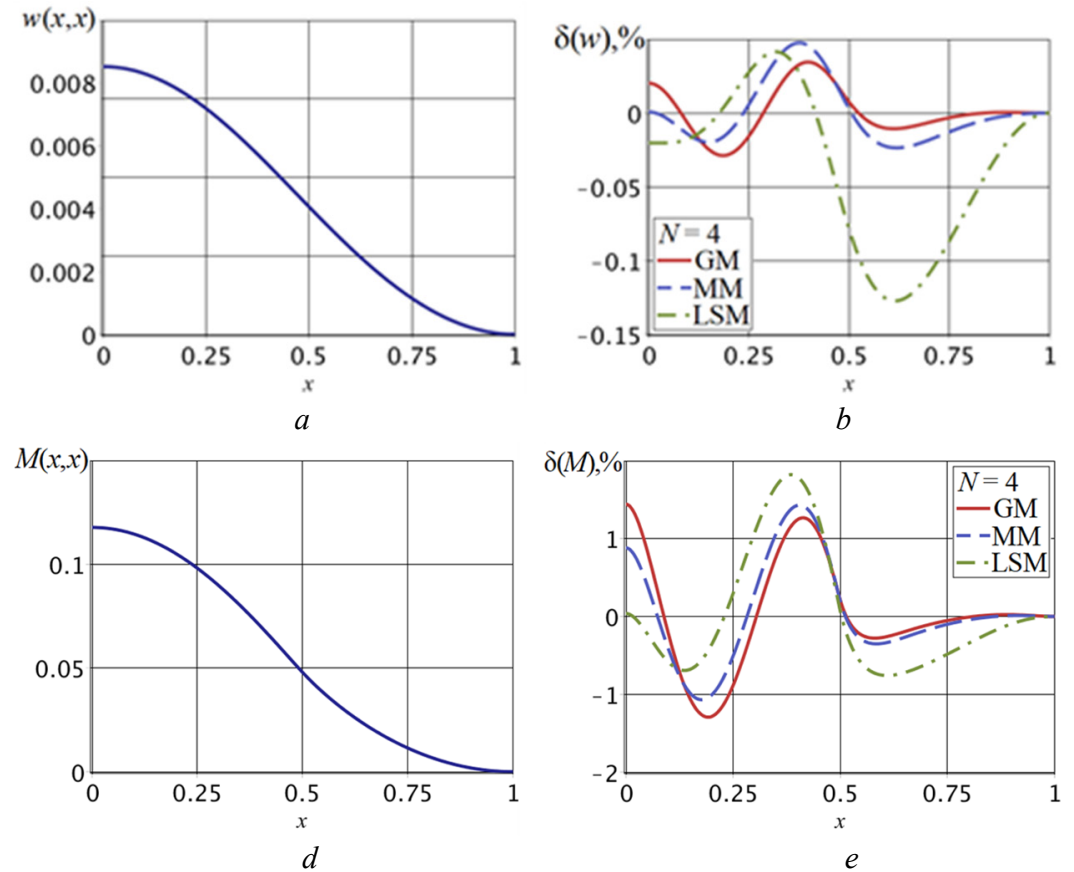

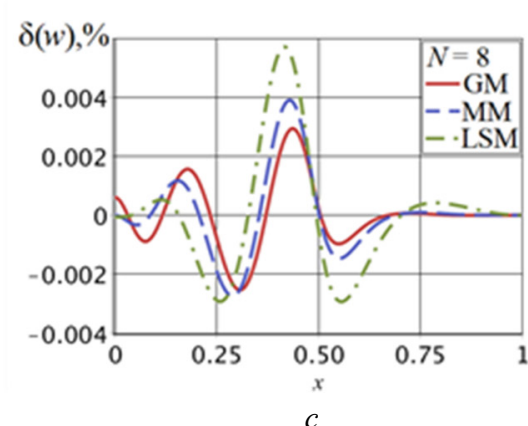

$c$

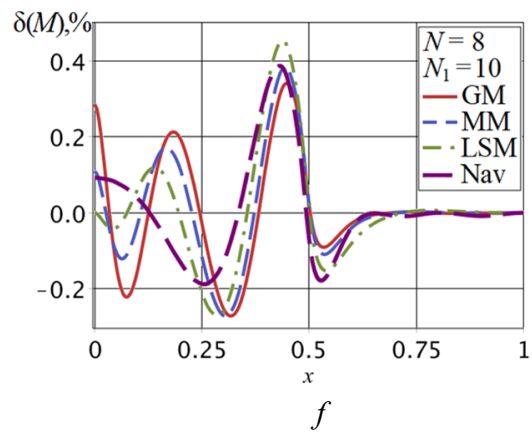

Fig. 3. Exact displacements $(a)$ and bending moments $(d)$ along axis $x=y(a)$, and their deviations by WRM calculated for $N=4(b, e)$ and $N=8(c, f)$ at $u=v=0.5, L=3$

Evidently that all variants of WRM demonstrate very impressive accuracies, while for moments the bigger number of terms is required to get the same accuracy.

For comparison, the deviation of 10 terms $\left(N_{1}=10\right)$ Navier solution from the exact one is also shown on Fig. 3, $f$. So, we can state also very good accuracy of Navier method for this case. Furthermore, Navier method is much simpler in technical realization here, so the further analysis for justification of our method is needed.

Thus consider two cases of concentrated loading. First case is the when the loading is applied on central square part with both sides equal to $u=v=0.1$. It means that only 0.01 of the whole area is loaded. The second case relates to more abrupt loading: $u=v=0.04$, i. e. only 0.0016 part of plate area is loaded. The results (only for moments, because for displacements they are much accurate) of moment deviations are depicted on Fig. 4. The results for $u=v=0.1$ are given on Fig. $4, a$ at $N=8$ for all three variants of WRM realization. With comparison purpose we give here the deviation of Navier results for $N_{1}=20$. It is evident, that 8 terms analysis in all variants of exponential functions based WRM are not worse than 20 terms Navier analysis.

With decreasing the area of loading the deviance for the same number of terms, $N=8$, increases from overage value $\approx 1 \%$ at $u=v=0.1$ up to $1.5 \%$ for $u=v=$ $=0.04$. Navier method produces worse results and at $u=$
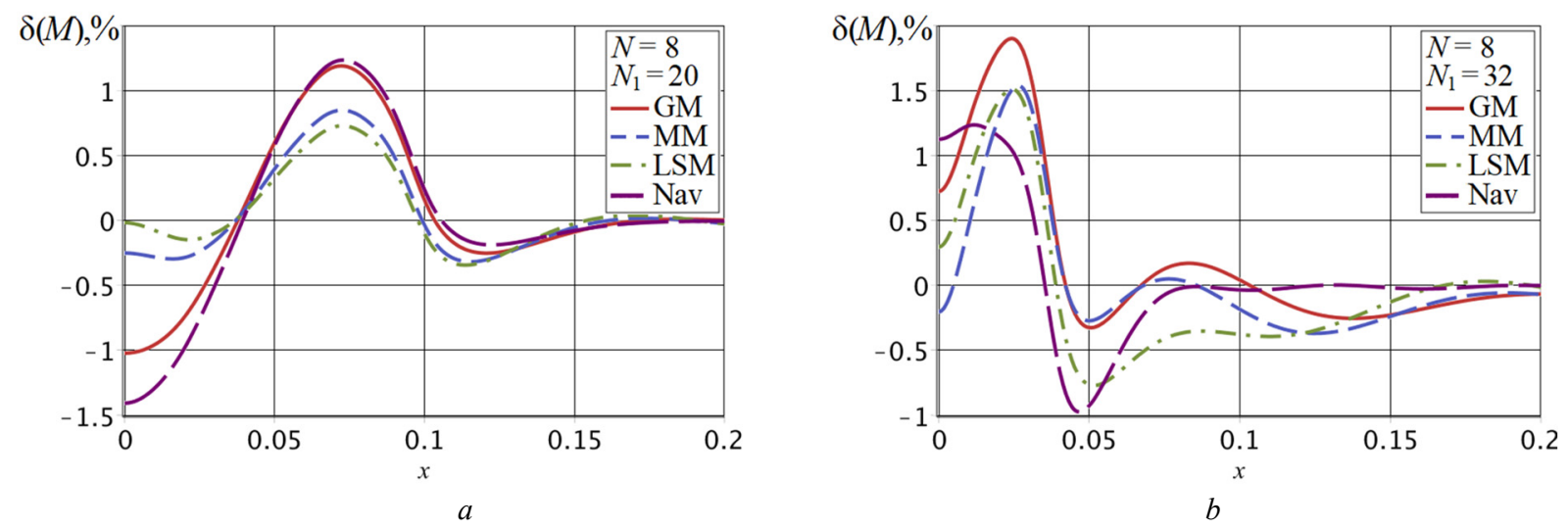

Fig. 4. Calculated deviations of the bending moments at $u=v=0.1(a)$ and $u=v=0.04(b)$ 
$=v=0.04$ loading it requires approximately 32 terms $\left(N_{1}=32\right)$ to gives the comparable accuracy with $N=8$ in WRM.

Look again on Fig. 4 and Fig. 3, $f$, which give the moment deviation. These deviations are product of two factors. First one is the scale (maximal value) of the calculated approximate dependence; second one is the change of form of dependence. For example, calculated graph can be slightly wider or shifted with respect to the true one. Of, course, in practical application we are mostly interested in maximums of functions. So, investigate the deviations at the point $(x=0, y=0)$, where the local maximum is attained. Introduce the measure of deviation of moments, $\delta_{N}$, for the whole area, which is the difference between the exact maximum and calculated one:

$$
\delta_{N}=\frac{M_{\text {exact }}^{\max }-M_{N}^{\max }}{M_{\text {exact }}^{\max }} \cdot 100 \% .
$$

The results of $\delta_{N}$ determination are given in

Table 1. It allows to draw more definite conclusions with respect to accuracy of different variants of our WRM realization and Navier method. First, the efficiency of exponential based WRM as compared with Navier results increases when the loading become more concentrated. For example, for $u=v=1$ both approaches require a comparable number of terms. When the loading is very concentrated, say $u=v=0.04$, the similar accuracy can be attained for 8 terms in WRM and for $80-100$ terms in Navier method. It should be remembering that 8 terms actu- ally means $8 \cdot 8=64$ coefficients, while 100 terms means $10^{4}$ coefficients. Second, Galerkin method (GM) is not the best option for calculation of moments. Method of moments (MM) and least square method (LSM) are better choices for this particular task.

As was said before, the only semi - arbitrary parameters in proposed WRM realization are the scaling lengths $L_{x}, L_{y}$. We think, that necessary to adopt some scaling factor was the main hindrance, which prevented to use them so far. In case of using the sin and cos functions the scaling factors are quite natural and are related with boundary conditions (plate dimensions) more univocally. Here of course, scaling factors are related with dimensions, too. But, with increase of number of element, it becomes more and more abrupt, i.e. with very outstanding sole maximum. To provide some smoothness, it is necessary to take $L_{x}, L_{y}$ slightly bigger than characteristic dimension. This point requires some numeric investigation.

Consider the local loading over the area $|x| \leq 0.1 a$, and $|y| \leq 0.1 a$. Calculate according to (17b) the moments deviations at different values of $L_{x}=L_{y}=\{1,2,3\}$ for the same number of terms $N=6$. The results of calculation are shown on Fig. 5. First, we can notice, that overage deviations for all three cases (scaling factors) are similar.

From other hand, it can be noticed that for LSM at $L=1$, there is systematic deviation (all deviations are negative), this means the trial function have no "power"

Table 1. Deviation of calculated moment $M_{N}^{\max }$ according to WRM and Navier method

\begin{tabular}{|c|c|c|c|c|c|c|c|c|}
\hline \multirow{2}{*}{$u / a=v / b$} & \multicolumn{4}{|c|}{ Navier method, $\delta_{N}, \%$} & \multicolumn{3}{c|}{ Proposed method, $\delta_{N}, \%$} & $M_{\text {exact }}^{\max } \cong M_{N=400}^{\max }$ \\
\cline { 2 - 7 } & $N=20$ & $N=50$ & $N=100$ & $N=200$ & \multicolumn{3}{|c|}{$N=8$} & \multirow{2}{*}{$N=400$} \\
\cline { 3 - 7 } & & & & GM & MM & LSM & \\
\hline 0.04 & 8.984 & -1.044 & 0.165 & 0.017 & 0.745 & -0.182 & 0.317 & 0.378892 \\
\hline 0.1 & -1.385 & 0.045 & -0.018 & 0.003 & -1.014 & -0.233 & 0.027 & 0.284116 \\
\hline 0.5 & -0.048 & 0.001 & 0 & 0 & 0.283 & 0.109 & -0.0005 & 0.117744 \\
\hline 1.0 & 0.021 & -0.001 & 0 & 0 & -0.0007 & -0.0006 & -0.0001 & 0.047886 \\
\hline
\end{tabular}
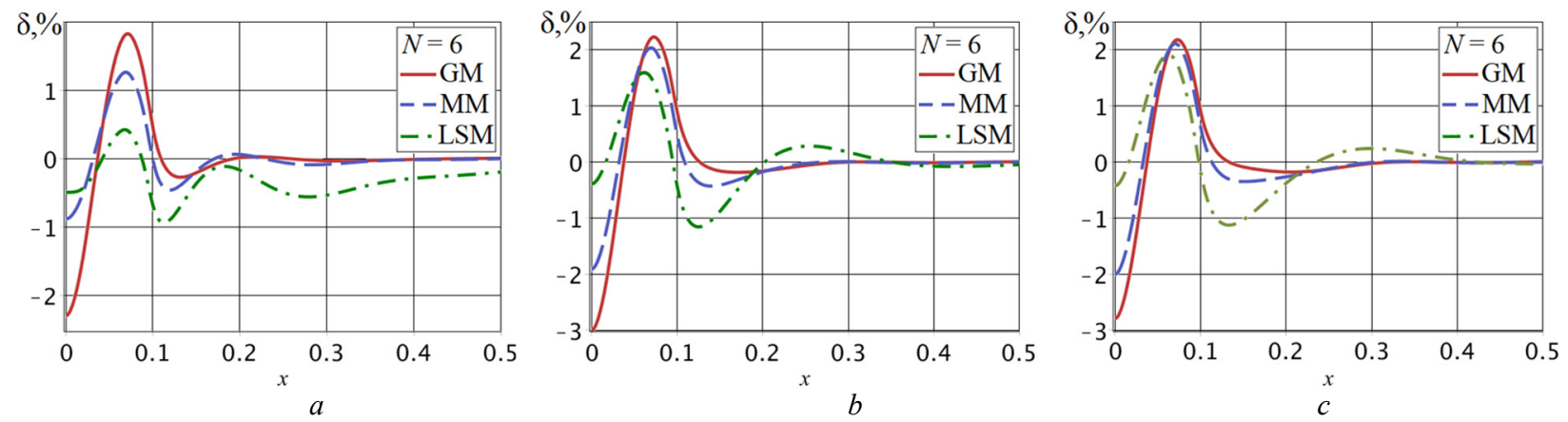

Fig. 5. Calculated deviations of bending moment at $L_{x}=L_{y}=1(a), L_{x}=L_{y}=2(b), L_{x}=L_{y}=3(c) ; u / a=0.1$ 
,they are not able to provide correct result at points far from the origin. So, within reasonable limits the value of $L$ has no influence on character and accuracy of solution. So, we mostly take it to be in ranges from 2 to 4 .

Simply - supported plate, eccentric load. This case is characterized by two points. First, here and below we return to more universal functions $(7 b),(7 c)$. Second, it is intuitively clear, that eccentric loading leads to eccentric deformation, where it might be more advantageous to use the eccentric trial function $\Psi_{k, m}(x, y)$. This possibility pertains to peculiarities of our method, so it is interesting to investigate this. Note, that traditional sinus functions do not allow this.

As example, consider the slightly concentrated eccentric uniform loading acting on area $-0.8 \leq x \leq-0.4$, $-0.8 \leq y \leq-0.4$ :

$$
\begin{aligned}
& p(x, y)=\frac{1}{(0.4 \cdot 0.4)}\left\{\begin{array}{cc}
1, & \text { if }-0.8 \leq x \leq-0.4 \\
0, & \text { elsewhere }
\end{array}\right. \\
& \text { and }-0.8 \leq y \leq-0.4
\end{aligned}
$$

Results of multivariate calculation of maximal deviation of approximate moments according to definition (17) by WRM for number of terms equal to 7 are presented in Table 2. Here we presented results as for usual symmetrical approach, as well as to the "shifted" approach, when the mean value of $K_{m}=\left(K_{1}+K_{2}\right) / 2$ is taken to be negative (for $M_{m}$ is the same). The exact value of maximal bending moment is determined from Navier solution at $N_{1}$ equal to 200. A number of interesting conclusions can be drawn from these results:

- as expected, the usual "symmetrical" solution, when $-K_{1}=-M_{1}=K_{2}=M_{2}=3$ is nor the best choice for eccentric loading;

- for symmetrical approach the scaling length, $L$, is not essential and provides the similar results for relatively wide range of its values. Here the deviations are near $8 \%$;
- the shifting of the mean trial function number can drastically increase the accuracy;

- the bigger is the shift to the left (to negative side) the bigger scaling length should be taken to provide the best accuracy; the deviation can be as low as approximatly $1 \%$;

- choice of weight function have minor influence on accuracy, nevertheless it is evident that MM and LSM have some advantage over Galerkin method.

To understand the whole picture about deviations we present the exact displacements and bending moments on Fig. 6, $a$ and Fig. 6, $c$ accordingly for geometry and loading considered. The deviation, calculated according to (17a), along line $x=y$ are given on Fig. $6, b-$ for displacements and on Fig. $6, d$-for moments. In calculation we use the shifted functions, where $N=8$ and $K_{1}=-8$ and $K_{2}=-1$. In spite that deviation may be as big as $4 \%$, here the deviation of the maximal value is not bigger than $0.3 \%$. So, the accuracy is quite good. It is interesting to know that similar accuracy for limited number of terms in Navier method is attained at approximately 26 terms. Notice again that Galerkin method is worse as compared with LSM.

Free vibration of a simply supported plate. Note, that only Galerkin method is used for free vibration analysis. Here the shifting of trial function have no sense, so the basic functions $\Phi_{k}(x), \Phi_{m}(y)$ are constructed according to formulas (7b) and (7c), where $-K_{1}=K_{2}$, $-M_{1}=M_{2}$. This SSSS configuration is very important for understanding of the efficiency of our method, because only for it there is an accurate solution, while for our method this case presents no additional advantages as compared with other geometries. So the real accuracy of method can be demonstrated.

We have started our calculation for only one trial function, where $K_{1}=M_{1}=0$ at $L=2$. This one term approximation allows to get only one frequency, so we got $\omega_{1} \approx 4.9393$. The relative deviation of it from the

Table 2. Deviation from the maximum bending moment $\delta(M), \%$ calculated for $N=7, M_{\text {exact }}^{\max } \cong 0.14691$

\begin{tabular}{|c|c|c|c|c|c|c|c|c|}
\hline $\begin{array}{c}\text { Weight func- } \\
\text { tions }\end{array}$ & \multicolumn{9}{|c|}{$\Omega_{k, m}(x, y)$, LSM } & $\begin{array}{c}\Theta_{k, m}(x, y), \\
\text { MM }\end{array}$ & $\Psi_{k, m}(x, y), \mathrm{GM}$ \\
\hline$\left[K_{1} ; K_{2}\right]$ & {$[-3 ; 3]$} & {$[-5 ; 1]$} & {$[-6 ; 0]$} & $\begin{array}{r}{[-7 ;-} \\
1]\end{array}$ & $\begin{array}{c}{[-8 ;-} \\
2]\end{array}$ & {$[-9 ;-3]$} & {$[-7 ;-1]$} & {$[-7 ;-1]$} \\
\hline $\mathrm{L}=0.8$ & 7.024 & 2.858 & -0.293 & -0.423 & 1.388 & 12.968 & -1.051 & -2.118 \\
\hline $\mathrm{L}=1$ & 8.575 & 2.928 & 0.835 & -0.581 & -0.338 & 10.668 & -0.792 & -0.834 \\
\hline $\mathrm{L}=2$ & 8.823 & 1.908 & 1.192 & 1.629 & 1.549 & 0.535 & -0.131 & -0.703 \\
\hline $\mathrm{L}=3$ & 8.602 & 3.751 & 1.908 & 1.093 & 1.094 & 1.405 & 0.973 & 1.142 \\
\hline $\mathrm{L}=5$ & 8.461 & 5.793 & 4.269 & 2.929 & 1.912 & 1.266 & 3.162 & 2.428 \\
\hline
\end{tabular}




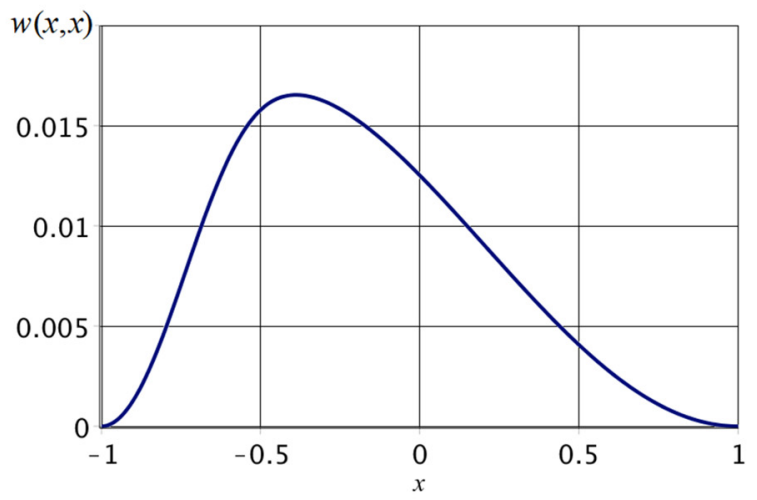

$a$

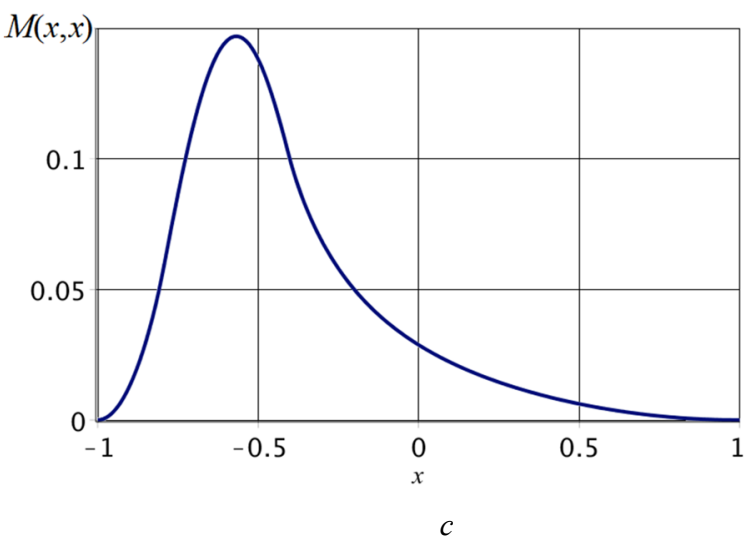

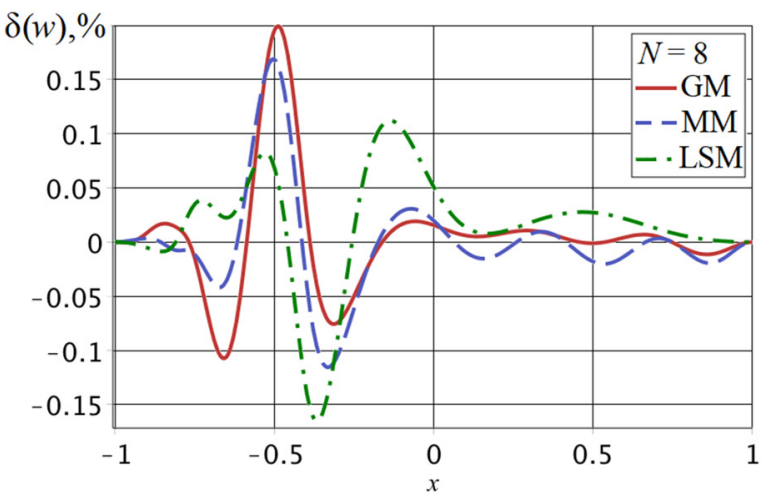

$b$

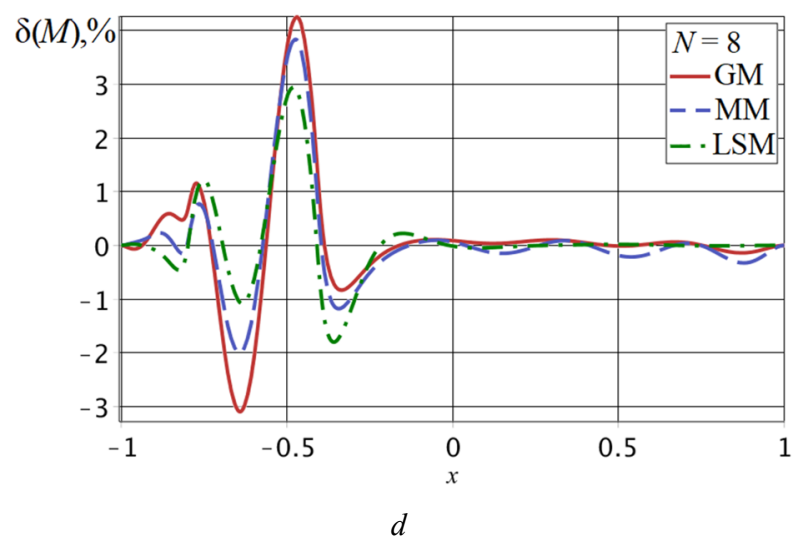

Fig. 6. Exact displacement $(a)$, bending moment $(c)$ and calculated deviations from them $(b, d)$ at $K_{1}=-8, K_{2}=-1$

accurate value (formula (6b)) is equal to: $\delta\left(\omega_{1}\right)=\frac{|4.9348-4.9393|}{4.9348} \cdot 100 \% \approx 0.091 \%$. This is unexpectedly good result.

Letting $K_{1}=M_{1}=-1$ the frequency equation (13d) becomes a polynomial of $9^{\text {th }}$ order with respect to unk- nown $\omega^{2}$. These 9 frequencies are calculated and given in Table 3. Multiple roots have the double numeration in first column. The calculations were performed for three different values of the scaling length $L_{x}=\{2,3,5\}$. Here, the increase of $L_{x}$ leads to a little better accuracy. The results are shown in Table 3. For example, for first fre-

Table 3. Deviations of the calculated dimensionless frequencies

\begin{tabular}{|c|c|c|c|c|c|c|c|c|}
\hline \multirow{2}{*}{$\begin{array}{c}\text { Number of } \\
\text { frequency }\end{array}$} & \multicolumn{2}{|c|}{ Exact value, (6b) } & \multicolumn{5}{c|}{ Proposed method $(\mathrm{GM}), \delta\left(\omega_{i}\right), \%$} \\
\cline { 2 - 9 } & $k, n$ & $\omega_{i}$ & \multicolumn{2}{|c|}{$L_{x}=L_{y}=2$} & \multicolumn{2}{|c|}{$L_{x}=L_{y}=3$} & \multicolumn{2}{c|}{$L_{x}=L_{y}=5$} \\
\cline { 4 - 10 } & & $N=3$ & $N=5$ & $N=3$ & $N=5$ & $N=3$ & $N=5$ \\
\hline 1 & 1,1 & 4.93480 & $1 \mathrm{e}^{-4}$ & $7.6 \mathrm{e}^{-8}$ & $4 \mathrm{e}^{-5}$ & $1.2 \mathrm{e}^{-8}$ & $2 \mathrm{e}^{-5}$ & $3.4 \mathrm{e}^{-9}$ \\
\hline 2,3 & 1,$2 ; 2,1$ & 12.3370 & 0.930 & 0.006 & 0.717 & 0.003 & 0.621 & 0.002 \\
\hline 4 & 2,2 & 19.7392 & 0.914 & 0.006 & 0.705 & 0.003 & 0.611 & 0.002 \\
\hline 5,6 & 1,$3 ; 3,1$ & 24.6740 & 2.919 & 0.051 & 2.621 & 0.039 & 2.475 & 0.034 \\
\hline 7,8 & 2,$3 ; 3,2$ & 32.0762 & 2.230 & 0.035 & 1.973 & 0.026 & 1.849 & 0.022 \\
\hline 9 & 3,3 & 44.4132 & 2.548 & 0.040 & 2.288 & 0.030 & 2.161 & 0.026 \\
\hline
\end{tabular}


quency the increasing of scaling length from 2 to 5 leads to increase of accuracy (deviation decreases from $0.0001 \%$ to $0.00002 \%$ ). For other frequencies up to ninth one the deviation may be as big as $0.62 \%-2.92 \%$.

Letting $K_{1}=M_{1}=-2$ the system contains 25 which allows to find 25 roots. Of course, the larger the number of frequency the lesser is the accuracy of its determination. So we restrict ourselves only with first 9 roots (frequencies). They also are given in Table 3. Such comparatively small increase in number of unknowns leads to drastic increase of accuracy. The relative deviations of the first nine frequencies $\delta\left(\omega_{i}\right) \quad 1 \leq i \leq 9$ are confined within range from $3.4 \cdot 10^{-8} \%$ for first frequency up to $0.034 \%$ for the ninth one. We consider these results as perfect one, which demonstrates the great efficiency of the method.

Free vibration for all sides clamped plate. CCCC plate is very often calculated for comparison purposes. CCCC plate can not be solved analytically, so the efficiency of different approximate methods is usually demonstrated for it. Namely this geometry was chosen in comparison study of different popular methods in work [14].

In our analysis we use $N=5$ (25 degrees of freedom, DOF), $N=7$ (49 DOF), and $N=9$ (81 DOF). For this case there is no exact solution, and which number is closer to "exact" one, we only can guess. So in Table 4 we give our results as well as the results of the most respected investigators. Note some interesting results.
The 25 - equations approach was not able to find $9^{\text {th }}$ and $10^{\text {th }}$ frequencies. All other frequencies were determined with good accuracy. Results for 49 - equations approach differ from 81 - equations approach for first 8 frequencies by less than $0.003 \%$, while the $12^{\text {th }}$ frequency differ on $0.5 \%$. Comparison with previous authors shows some minor difference, for example, the differences for first 4 frequencies with classic work of Leissa A.W. [10], Blevins recent handbook [22], where old results of Durvasula S. [23] are used there, Gorman D. [24] is confined withing $0.03 \%$. Of course, this is not a big difference, but it is interesting to know which results are more exact. So, a resent work of $\mathrm{El}$ - Gamel M. at all [21], where approximately $N=200$ terms were used (this means $N^{2}$ equations), can shed light on the value of "exact" values. They gave only first four frequencies. But the biggest difference (for $4^{\text {th }}$ one) with our results is smaller than $0.0002 \%$ So, we can state a very exiting accuracy of our approach for comparatively small number of DOF used.

\section{Conclusions}

In this work we apply to rectangular plate analysis the new variant of WRM based on the sets of consequent exponential functions. The following results with respect to methods application and its accuracy on example of square plate with side equal to 1 are attained.

1. For static analysis only SSSS plate was investigated, for which the exact solution exists. In general pro-

Table 4. Comparison of dimensionless frequencies for CCCC square plate

\begin{tabular}{|c|c|c|c|c|c|c|c|}
\hline \multirow{2}{*}{ № } & \multicolumn{3}{|c|}{ Proposed method, GM } & \multirow{2}{*}{$\begin{array}{l}\text { El-Gamel } \\
\text { M., } \\
\text { Ref. [21] }\end{array}$} & \multirow{2}{*}{$\begin{array}{l}\text { Blevins R., } \\
\text { Ref. [22] }\end{array}$} & \multirow{2}{*}{$\begin{array}{c}\text { Leissa A.W., } \\
\text { Ref. [10] }\end{array}$} & \multirow{2}{*}{$\begin{array}{c}\text { Gorman D., } \\
\text { Ref. [24] }\end{array}$} \\
\hline & $N=5$ & $N=7$ & $N=9$ & & & & \\
\hline 1 & 35.9855 & 35.985217 & 35.985193 & 35.985191 & 35.9915 & 35.992 & 35.984 \\
\hline 2 & 73.4137 & 73.394121 & 73.393877 & 73.393857 & 73.413 & 73.413 & 73.40 \\
\hline 3 & 73.4137 & 73.394121 & 73.393877 & 73.393878 & 73.413 & 73.413 & 73.40 \\
\hline 4 & 108.2589 & 108.217880 & 108.216711 & 108.216517 & 108.269 & 108.27 & 108.20 \\
\hline 5 & 131.7900 & 131.582561 & 131.580782 & & 131.641 & 131.64 & 131.92 \\
\hline 6 & 132.4211 & 132.207247 & 132.204900 & & 132.243 & 132.24 & 131.92 \\
\hline 7 & 165.2058 & 165.003733 & 165.000815 & & $165.158^{\mathrm{e}}$ & & 165.00 \\
\hline 8 & 165.2058 & 165.003733 & 165.000815 & & $165.158^{\mathrm{e}}$ & & 165.00 \\
\hline 9 & - & 211.772117 & 210.547862 & & & & 210.52 \\
\hline 10 & - & 211.772117 & 210.547862 & & & & 210.52 \\
\hline 11 & 220.3309 & 220.035401 & 220.033243 & & & & 220.04 \\
\hline 12 & 231.7419 & 243.192875 & 242.172416 & & & & 242.28 \\
\hline
\end{tabular}


posed method requires lesser terms than Navier method. The more concentrated is outer loading the lesser terms are required in proposed method as compared with Navier solution to achieve the similar accuracy. For example, for the central uniform loading on a square with side equals to 0.04 , proposed 8 - terms solution is comparable with 80 - terms Navier solution.

2. The method has unique feature to effectively treat eccentric loading by considering only eccentric terms (shifted to the same direction with respect to the symmetric function with number 0 ). This can essentially decrease the required number of terms.

3. Accuracy of WRM depends in some extend on the proper choice of weight function. Three different variants of them were investigated: Galerkin method, Least square method and Moment methods. In general, this choice has no drastic effect on accuracy, nevertheless LSM can be considered as the best choice.

4. There is only one semi arbitrary parameter in our trial functions - scaling length $L$. It was shown on many static and free vibration examples that optimally it can be chosen in the range of $2-4$ times of characteristic dimension of plate. In this range the choice of $L$ has minor influence on results.

5. Analysis of frequencies for free vibration of SSSS and CCCC plates demonstrates a very remarkable accuracy of the method which exceeds other ones with respect to accuracy. Technique of method application for free vibration almost does not differ from the static analysis and is very simple and easy to implement.

\section{References}

[1] I.V. Orynyak, Y.P. Bai, "Application of exponential functions in weighted residuals method in structural mechanics on example of axisymmetrical shell problem”, Mechanics and Advanced Technologies, no 3 (90), 2020, pp. 19-28. https://doi.org/10.20535/2521-1943.2020.0.209618

[2] C.A.J. Fletcher. Computational Galerkin methods. New - York, USA: Springer - Verlag, 1984. https://doi.org/10.1007/978-3-642-85949-6

[3] K.-J. Bathe, Finite Element Procedures. 2nd ed, Watertown, New - York, USA: 2016.

[4] M.J. Gander and G. Wanner, "From Euler, Ritz, and Galerkin to modern computing", SIAM Review, 2012, vol. 54, no. 4, pp. 627-666. https://doi.org/10.1137/100804036

[5] A.W Leissa, "The historical bases of the Rayleigh and Ritz methods", Journal of Sound and Vibration, vol. 287, no 4 - 5, pp. 961-978, 2005. https://doi.org/10.1016/j.jsv.2004.12.021

[6] A.S. Sayyad, "On the free vibration analysis of laminated composite and sandwich plates: A review of recent literature with some numerical results", Composite Structures, vol. 129, pp. 177-201, 2015.

doi: 10.1016/j.compstruct.2015.04.007

[7] S.P. Timoshenko, S. Woinowsky - Krieger. Theory of plates and shells. New York, USA: McGraw - Hill, 1959.

[8] V. Meleshko. "Bending of an elastic rectangular clamped plate: exact versus "engineering" solutions", Journal of Elasticity, vol. 48, pp. 1-50, 1997. doi: 10.1023/A:1007472709175

[9] W. Voigt, "Bemerkungen zu dem problem der transversalen schwingungen rechteckiger platten“, Nachr. Ges. Wiss., no. 6, pp. 225-230, 1893.

[10] A.W. Leissa, "The free vibration of rectangular plates", Journal of Sound and Vibration, vol. 31, no. 3, pp. $257-293,1973$. doi: 10.1016/S0022-460X(73)80371-2

[11] D.J. Gorman, S.D. Yu, "A review of the superposition method for computing free vibration eigenvalues of elastic structures", Computers Structures, vol. 104-105, pp. 27 - 37, 2012. doi: 10.1016/j.compstruc.2012.02.018

[12] R. Banerjee et al., "Dynamic stiffness matrix of a rectangular plate for the general case, Journal of Sound and Vibration, vol. 342, pp. 177-199, 2015. doi: 10.1016/j.jsv.2014.12.031

[13] G.B. Warburton, "The vibration of rectangular plates", in Proc. Inst. Mech. Engrs., vol. 168, pp. 371-384, 1954. doi: 10.1243/PIME_PROC_1954_168_040_02

[14] P. Moreno-García et al., "A review and study on Ritz method admissible functions with emphasis on buckling and free vibration of isotropic and anisotropic beams and plates", Archives of Computational Methods in Engineering, vol. 25, pp. 785 - 815, 2018. doi: 10.1007/s11831-017-9214-7

[15] D. Young, "Vibration of rectangular plates by the Ritz method", J Appl Mech, vol. 17, no. 4, pp. 448 - 453, 1950.

[16] J.R. Gartner "Improved numerical computation of uniform beam characteristic values and characteristic functions", J. Sound Vib, vol. 84, no. 2, pp. 481-489, 1982. doi: 10.1016/S0022-460X(82)80029-1

[17] R.B. Bhat," Natural frequencies of rectangular plates using characteristic orthogonal polynomials in Rayleigh-Ritz method", J. Sound Vib., vol. 102, no. 4, pp. 493-499, 1985. doi: 10.1016/S0022-460X(85)80109-7

[18] C.S. Kim et al., "On the flexural vibration of rectangular plates approached by using simple polynomials in the Rayleigh-Ritz method", Journal of Sound and Vibration, vol. 143, no 3, pp. 379 - 394, 1990. doi: 10.1016/0022-460X(90)90730-N

[19] G.B. Chai, "Free vibration of rectangular isotropic plates with and without a concentrated mass", Comput Struct, vol. 48, no. 3, pp. 529-533, 1993. doi: 10.1016/0045-7949(93)90331-7 
[20] D. Zhou, "Natural frequencies of rectangular plates using a set of static beam functions in Rayleigh-Ritz method", Journal of Sound and Vibration, vol. 189, no. 1, pp. 81-87, 1996. doi: 10.1006/jsvi.1996.0006

[21] M. El-Gamel et al., "Sinc-Galerkin solution to the clamped plate eigenvalue problem", SeMA Journal, vol. 74, pp. 165-180, 2017. doi: 10.1007/s40324-016-0086-9

[22] R.D. Blevins, "Formulas for dynamics, acoustics and vibration", in Natural frequency of plates and shells, New Jersey, USA: John Wiley and Sons, 2016, ch.5. doi: 10.1002/9781119038122.ch5

[23] S. Durvasula, "Natural frequencies and modes of clamped skew plates", AIAA Journal, vol. 7, pp. 1164-1167, 1969. https://doi.org/10.2514/3.5296

[24] D.J. Gorman, Free vibration analysis of rectangular plates. Amsterdam: Elsevier, 1982. https://doi.org/10.1115/1.3162564

\title{
Применение экспоненциальных функций в методе взвешенных невязок в структурной механике на примере статического и вибрационного анализа прямоугольной пластины
}

\author{
И. В. Орыняк, Ю. П. Бай
}

Аннотация. Данное исследование является продолжением наших усилий по применению специально построенных наборов последовательных экспоненциальных функций как пробных (базисных) функиий в методе взвешенных невязок (МВН) на примере классических задач структурной механики. Статья не направлена на получение новых результатов, а посвящена обоснованию эффективности предлагаемого метода. Рассматриваются статическая деформация и свободные колебания изотропной тонкостенной квадратной пластины. Особенностью работы является выбор весовых (поверочных) функиий в трех вариантах: как пробных функиий (метод Галеркина, МГ); как функиий, являюшихся результатом применения дифференциального оператора к пробным функиий (метод наименьших квадратов, МНК); как функций, являюшихся произведениями вторых производных от пробных функиий по х и у (метод моментов, ММ). Решение строится как произведение двух независимых множеств функиий относительно координат х и у. Каждое множество представляет собой комбинацию пяти последовательных экспоненциальных функций, в которой первый коэффициент равен 1, а четыре другие коэффициента определяются из граничных условий на противоположных сторонах пластины. Произвольнылм параметром в методе является коэффициент масштабирования в показателях, разумный диапазон которого тщзательно исследовался, и показано его влияние на результаты.

Статическая деформация исследована на примере простой шарнирно-опертой пластины, когда внешняя нагрузка или симметрична и сосредоточена вблизи центра пластинь, или смещена от центра к произвольной угловой точке. Продемонстрировано, что результаты сходятся к точному решению быстрее, чем в классическом методе Навье. ММ и МНК дают лучшую точность при определении изгибающих моментов, чем МГ. Предложенный метод применен к анализу свободных колебаний пластины, точность результатов определения собственных частот является отличной даже при небольшом количестве членов ряда. Проанализированы сравнительно сложный случай - свободные колебания защемленной по всем сторонам пластины, достигнуты очень хорочие результаты по эффективности и точности.

Ключевые слова: прямоугольная пластина, смещенная нагрузка, метод взвешенных невязок, метод Бубнова-Галеркина, весовые функиии, свободные колебания пластины, защемленная пластина, собственные частоты.

\section{Застосування експоненціальних функцій в методі зважених нев'язок в структурній механіці на прикладі статичного та вібраційного аналізу прямокутної пластини}

\section{І. В. Ориняк, Ю. П. Бай}

Анотація. Дослідження є продовженням наших зусиль щэодо застосування спеціально побудованих наборів послідовних експоненціальних функиій як пробних (базисних) функиій в методі зважених нев'язок (МЗН) на прикладі класичних задач конструкційної механіки. Стаття не направлена на отримання нових результатів, а присвячена обтрунтуванню ефективності запропонованого методу. Розглядаються статична деформація та вільні коливання ізотропної тонкостінної квадратної пластини. Особливістю роботи є вибір вагових (перевірочних) функцій в трьох варіантах: як пробних функиій (метод Гальоркіна, МГ); як функиій, що є результатом застосування диференціального оператора до пробних функцій (метод найменших квадратів, МНК); як функцій, які є добутком других похідних від пробних функцій по х $і$ у (метод моментів, ММ). Розв'язок будується як добуток двох незалежних множин функиій відносно координат х та у. Кожна множина $є$ комбінацією п'яти послідовних експоненціальних функцій, де перший коефіцієнт дорівнює 1, а чотири інші коефіцієнти 
визначаються з граничних умов на протилежних сторонах пластини. Довільним параметром в методі є коефіцієнт масштабування в показниках, розумний діапазон якого ретельно досліджено і показано його вплив на результати.

Статична деформація досліджена на прикладі простої шарнірно-опертої пластини, коли зовнішнє навантаження або симетричне і зосереджене поблизу иентру пластини, або зміщене від центра до будь-якої кутової точки. Продемонстровано, шүо результати сходяться до точного рішення швидше, ніж у класичному методі Нав'є. ММ та МНК дають кращу точність при визначенні згинаючих моментів, ніж МГ. Запропонований метод застосований до аналізу вільних коливань пластини, точність результатів визначення власних частот є відмінною навіть при невеликій кількості членів ряду. Проаналізовано порівняно складний випадок - вільні коливання защемленої на всіх сторонах пластини, досягнуто дуже хороших результатів щуодо ефективності та точності.

Ключові слова: прямокутна пластина, зміщене навантаження, метод зважених нев'язок, метод Бубнова-Гальоркіна, вагові функиї, вільні коливання пластини, защемлена пластина, власні частоти. 